Brit. F. industr. Med., 1966, 23, 173

\title{
The Safety of Physically Disabled Drivers
}

\author{
LARS YSANDER \\ From the County Hospital, Varberg, Sweden, in collaboration with \\ the Institute of Social Medicine, Stockholm
}

Four hundred and ninety-four disabled drivers, the majority with loss of function in the legs usually as the result of poliomyelitis or amputations, have been studied with respect to the frequency of traffic accidents and serious traffic offences during a ro-year period. Traffic accidents which may have been caused by their disability occurred in only three $(0.6 \%)$ of the total number of drivers investigated. In all three cases the driver had loss of function in the right leg.

A comparison was made between the investigation series and a control series identical as regards sex, age, and licence-holding period but with a shorter exposure to traffic than the investigation series. The frequency of traffic accidents amounted to $7 \cdot 1 \%$ in both series, and the frequency of serious traffic offences was $12 \cdot 2 \%$ in the investigation series and $14.8 \%$ in the control series. Disabled drivers are not an increased hazard in traffic. The compensatory technical modifications to the vehicle which are generally adopted appeared to be adequate. However, there was a relatively increased frequency of accidents among drivers with loss of function in the right leg or right arm. An improvement of the technical modifications applied in these cases might result in a further reduction of the road-safety risks.

The literature on the significance in road safety of disabled drivers is sparse. An investigation from Frankfurt showed that there were only $0.07 \%$ of disabled persons among the drivers causing traffic accidents (Witt, 1960), and another German study established that disabled drivers were responsible for only 0.3 to $0.4 \%$ of the road accidents in the investigation area (Ganster, I963).

The Swedish Central Committee for the Care of the Crippled (Svenska Vanförevårdens Centralkommitté $-S V C K$ ) reported in 1960 on the answers received in response to a questionnaire sent out to disabled motorists. A total of 690 drivers took part in this investigation and among these the predominant cause of the disability was sequelae to poliomyelitis. The vehicles for $20 \%$ of the drivers were equipped for hand operation only. The median figure for the reported annual distance driven was $12,660 \mathrm{~km}$. Of the drivers, $16 \%$ had on some occasion been involved in a road accident investigated by the police, in most instances during the last five years. In two-thirds of these accident cases, according to the statements made, the other party was responsible. The injuries incurred by the disabled motorists were of minor importance. A suitable control series, however, was lacking (SVCK, 1960).

Received for publication October 21, 1965.
In a recent study of chronically sick road drivers it was found that $4.1 \%$ were involved in road accidents and $9.8 \%$ were involved in road accidents and/or serious traffic offences. The corresponding figures for a control series identical with regard to sex, age, licence-holding period, and traffic exposure were $7.7 \%$ and $15.3 \%$. Traffic incidents which could be reasonably ascribed to the disease of the driver or its treatment were caused by $0.8 \%$ of all the drivers investigated (Ysander, 1965; 1966).

\section{Aims of the Present Investigation}

The questions dealt with in the present investigation are as follows:

I. To what extent is it possible, with the technical aids now available, to compensate for the disability of a handicapped driver and thereby to limit or eliminate the risk which the disability constitutes from the road-safety point of view?

2. Does any particular type of disablement constitute a greater hazard than others from a roadsafety point of view?

\section{Material and Methods}

Composition of the Investigated Series The series comprised motor-vehicle drivers with physical 
defects who had been granted driving licences up to the end of $196 I$ in the county of Gothenburg and Bohus and the county of Halland. The population of the region investigated is approximately 800,000 , of whom about 550,000 live in towns. The primary data have been taken from the lists maintained by the county administrative boards of drivers exempted from motor-vehicle taxation on the grounds of physical handicaps; and from the lists kept by the senior inspector of motor vehicles for the two counties of persons who had requested a preliminary opinion about their ability to obtain a driving licence in spite of certain physical handicaps.

Since January I, I960 all motor-vehicle drivers suffering from a high-grade permanent disability have been able to apply for exemption from motorvehicle taxation as a measure of assistance because of their special difficulties with regard to work and transportation (Royal Decree of May 15, 1959, SFS no. 163-165/59). Previously, the existence of special equipment in the vehicle was a precondition for financial aid for disabled drivers, but this requirement has since been relinquished.

The senior inspector of motor vehicles for the two counties keeps a record of all persons who approach him about the possibility of their obtaining a driving licence in spite of disablement. Such records have been maintained for the county of Gothenburg and Bohus since 1948, for the northern division of the county of Halland since 1949, and for the southern division of Halland since 1958. In I962 the list contained about 800 names. In addition to the drivers included in the present investigation the list included persons who did not subsequently pursue their request for a driving licence, or who never obtained a driving licence, or who applied for and obtained a driving licence after the end of $\mathrm{I} 96 \mathrm{I}$, i.e., outside the period covered by this investigation. Finally, the list also included persons who were physically handicapped though not to a degree justifying their inclusion in the group of disabled motorists. A number of persons could not be found in the driving-licence register owing to incomplete data concerning their names.

The material does not comprise all disabled motorists in the two counties because, apart from the special registration of drivers exempted from motor-vehicle taxation, the county administrative boards have no separate record of driving-licence holders who are disabled. As a rule, however, all disabled persons who wish to have a driving licence are referred to the senior inspector of motor vehicles for consideration of their ability to drive. On the basis of the inspector's register and that of the county administrative boards it may therefore be regarded as probable that the majority of disabled persons who have been provided with a driving licence in the two counties have been traced.

The material obtained from the registers mentioned has been supplemented with 16 drivers who were represented in the special register of the county administrative boards for persons given a conditional driving licence on account of chronic progressive disease. Of these 16 drivers, Io had multiple sclerosis. In these Io cases, disablement of the extremities, and the technical measures necessary to facilitate the driving of the car, were considered to be more important from the risk-creating point of view than the possible occurrence of a sudden downward trend of the disease. In the other six cases the risk of a progressive course was regarded as very small.

The material comprises, in all, 494 drivers, of whom 54 are from the county of Halland. The low proportion from Halland is obviously connected with the fact that it was not until 1958 that the southern division of that county was brought within the area of the motor-vehicle inspectorate for the county of Gothenburg and Bohus. Of the total number of drivers, 76 were women (15\%). In 374 cases the drivers had a specially designed disabled person's car, and 12 other drivers had a specially designed motor-cycle. One disabled driver had a commercial vehicle licence. In 40 cases the drivers had held driving licences for cars or motor-cycles for varying periods before the appearance of the disablement. The average period for possession of a driving licence before disablement was is years. The licence-holding period for these drivers has, however, been calculated from the beginning of the disablement.

The material is divided according to the degree of disablement into the following three groups:

Group I In this group are drivers with a disability which permits only hand manipulation of the vehicle. These number 94 , or $19 \%$ of the whole series. The average period for possession of a driving licence as a disabled person was eight years.

Group 2 In this group are drivers with a disability such that it is possible for them to drive a vehicle after minor modification of the controls. These number 292 , or $59 \%$ of the whole series. The average period for possession of a driving licence as a disabled person was 6.6 years.

Group 3 In this group are drivers with a slight disablement only, such that a vehicle can be driven without any modification of the controls. These number 108, or $22 \%$ of the whole series. The average period for possession of a driving licence was 8.9 years. 
For the purposes of the present study, in each case a scrutiny was made of the medical certificates (including a specialist opinion) submitted with the licence application and of the opinion of the senior inspector of motor vehicles regarding the fitness of the applicant and any necessary technical modifications required for the vehicle. Further supplementary information concerning the disability status was not obtained either from the health insurance authorities or from the licence holders themselves.

Available data concerning road accidents and traffic offences were registered. Police records, court decisions, and other documents concerning traffic offences are preserved by the authorities for a limited period only. There are no data regarding occurrences of this kind before 1952. The investigation thus comprises the Io-year period 1952-6I and, for each driver, only that part of this period during which he was disabled. For the three groups together the average period of observation for possession of a driving licence as a disabled person during this I0-year period was 6.5 years.

Distribution of Various Types of Loss of Function The distribution and the compensatory technical measures needed are shown below:-

(a) Thirty-five drivers ( $7 \%$ ) had loss of function in the right arm or hand. The different measures of a technical nature prescribed in order to compensate for the loss of function among these drivers were left-hand driving, steering-wheel jknob, anti-slip steering wheel, automatic transmission or gear lever to the left of the steering wheel, or foot-operated transmission as well as horn and direction indicators fitted for operation with the left hand, and other appropriate changes of the controls in individual cases.

(b) Thirty-seven drivers ( $8 \%$ ) had loss of function in the left arm or hand. In general, the compensatory measures prescribed were similar to those given in (a) above.

(c) Ninety-six drivers (19\%) had loss of function in the right leg or foot. The compensatory measures prescribed were automatic transmission and accelerator pedal for the left foot or hand-operated throttle control, hand-operated brake, hand-operated lamp controls, and other modifications adapted to the individual concerned.

(d) One hundred and nine drivers $(22 \%)$ had loss of function in the left leg or foot. The compensatory measures were automatic transmission, handoperated clutch, hand-operated lamp controls, and other suitable modifications.

(e) Seventy-one drivers ( $14 \%$ ) had partial loss of function in both legs or both feet. The compensatory measures were similar to those listed under $(c)$ and $(d)$.

(f) Ninety-four drivers ( $19 \%$ ) had total loss of function in both legs. These drivers were compelled to use vehicles constructed for operation entirely by hand.

(g) For a further 52 drivers ( $11 \%$ ) other kinds of modification to the vehicle were required, such as modified pedals or special driving position owing to the driver's small stature.

Distribution of Different Disablement Causes The material has been divided (Table I) according to the reasons for disablement and into age groups. In 34 cases the diagnosis was not specified or the data did not indicate the type and degree of handicap. In group $I$, according to the earlier division, the after-effects of poliomyelitis, spinal tumours, and fractures predominate. In groups 2 and 3 the distribution by different diagnostic

TABLE I

Disabled Drivers: Reasons for Disablement and Ages

\begin{tabular}{|c|c|c|c|c|c|c|c|c|}
\hline \multirow[b]{2}{*}{ Reason for Disablement } & \multicolumn{8}{|c|}{ Age Group } \\
\hline & $18-$ & 2I- & 26- & $3 I-$ & $4^{I-}$ & $51-$ & $>60$ & Total \\
\hline After-effects of poliomyelitis & 8 & 19 & 19 & 65 & 44 & 26 & 9 & 190 \\
\hline Amputations & & 3 & II & 24 & 22 & 14 & 2 & 76 \\
\hline Polyarthritis and arthrosis deformans & $\mathbf{I}$ & 3 & 5 & 13 & 16 & 10 & 5 & 53 \\
\hline After-effects of tuberculosis of joints & & 2 & I & II & 18 & 8 & 3 & 43 \\
\hline Congenital malformations & & 5 & 7 & 8 & 4 & & $\mathbf{I}$ & 25 \\
\hline After-effects of trauma and fractures (excluding spinal injury) & & 3 & $\mathbf{I}$ & 5 & 6 & 7 & & 22 \\
\hline After-effects of spinal tumour and fracture & & 2 & 2 & 7 & 3 & 3 & $\mathbf{I}$ & 18 \\
\hline Organic nerve disease & & I & & 5 & 9 & & 2 & 17 \\
\hline Multiple sclerosis & & & & 7 & 5 & 4 & & 16 \\
\hline Unknown or unspecified conditions & & 2 & 2 & 4 & 12 & Io & 4 & 34 \\
\hline Total & 9 & 40 & 48 & 149 & 139 & 82 & 27 & 494 \\
\hline
\end{tabular}


groups is essentially similar, apart from some excess in group 3 of drivers with polyarthritis and the aftereffects of limb fractures, or other injuries.

Of the drivers with amputations, 29 had lost arms or hands, 20 the right leg, 21 the left leg, and six both legs. Of these drivers, 48 wore prostheses.

Comparison with Control Series It was not found practicable to obtain a control series which would have been representative of the population in the driving-licence registers in the two counties. The records are kept in alphabetical order without reference to sex, age, or licence-holding period, and cards for drivers who have died or moved from the county or had their licence revoked are not cancelled. The arrangements of this register made it impossible to obtain a control series which would have been representative for different sub-populations.

It was, however, considered useful to be able to compare the investigation series with a control series with respect to the frequency of road accidents and traffic offences, even though the control series would not meet the requirements for a representative sample. It was therefore decided to obtain a control series which would correspond to the investigation series with respect to the driver's sex, age, and licence-holding period, even though the comparison between the two series must be made with caution.

It is impossible to compare the frequency of accidents or traffic offences in the two series without a knowledge of the exposure to traffic of the individual driver and of the whole group, as expressed by the annual number of kilometres driven. A control series chosen according to the above-mentioned principles was, despite its limitations, considered to be the only practicable basis for an investigation and evaluation of the traffic exposure of healthy drivers in the investigation area, regard being paid to the probable difference in exposure to risk in different sex and age groups.

Method of Collecting the Control Series From the total licence-holding population in the records of the county administrative board in Gothenburg a systematic selection was made with quotas, the period being chosen at 150 . An endeavour was made to fill the same quotas as for the handicapped drivers, i.e., for $2 \times 7 \times 7=98$ types of individual (2 sexes, 7 age-groups, and 7 licence-holdingperiod groups). In practice this meant that data were examined in respect of each 150 th licenceholder in the list of driving-licence numbers kept by the board. The point of entry in these journals was chosen at random, and the books were gone through several times before all the quotas were filled. Only if the sex, age, and licence-holding period of an individual fitted in with the above-mentioned predetermined quota system was this driver included. The control series thus also consists of 494 drivers. Road accidents and serious offences occurring in this series during the ro-year period 1952-6r were recorded.

Questionnaire Enquiry In the questionnaire which was sent to the drivers in the investigation series as well as those in the control series the same annual-driving-distance distribution was applied as in the earlier investigation regarding chronically ill motorists (Ysander, 1966).

In the investigation series, 364 drivers were asked to state the number of kilometres driven in a year, the main purpose of the driving, the type of driving, and the time of driving. In this series, $130(26 \%)$ died during the period studied or could not be traced owing to insufficient information regarding their address. This loss of material is divided somewhat differently with regard to sex and age as compared with the investigation series as a whole. In the two groups of drivers aged 2I-25 years and over 60 years the loss was $40 \%$ and $56 \%$ respectively. In the other age groups the loss was between $22 \%$ and $29 \%$. The percentage of drivers in the investigation series who returned replies was $87 \%$. Drivers who did not return replies in spite of reminders were divided evenly over the whole investigation series.

In the control series, 395 drivers were requested in the same way to state the number of kilometres they had driven in a year. In this series, 99 $(25 \%)$ died during the investigation period or could not be traced owing to insufficient information about their address. This loss of material is distributed according to sex and age in the same way as the control series as a whole. The percentage of drivers in the control series who returned answers without having to be reminded was $73 \%$. After reminders had been sent the percentage rose to 87 . The drivers who did not reply were distributed evenly over the whole control series.

Evaluation of Road Accidents and Traffic Offences In this investigation the frequency of road accidents and traffic offences has necessarily been the sole criterion applied in assessing the safety in traffic of the drivers investigated. The disadvantages of such a basis of evaluation have been discussed earlier. All incidents which involved damage to property and possibly personal injury, and which in the majority of cases led to prosecution and conviction, have been counted as road accidents in this study. It was not found possible to 
distinguish between serious and minor road accidents. The following were regarded as serious traffic offences: drunken driving, or being an accessary thereto, careless driving, failure to stop at a major road, excessive speed, unlawful overtaking, driving a defectively equipped vehicle, and unlawful driving.

\section{Results and Discussion}

Accidents due to Disablement The first of the questions asked concerned the extent to which the technical measures applied could compensate for the driver's disability and limit the risk which this involved from a road-safety point of view. In the series there were during the Io-year period only three cases where defective or improperly designed technical equipment led to a wrong action or wrong manoeuvre resulting in a road accident:-

(I) A 42-year-old man suffering from the aftereffects of poliomyelitis had his car equipped with a hand-operated throttle and brake. He had driven his car for eight years. At an intersection he grasped the throttle instead of the brake and collided with a cyclist. In court he was found guilty of careless driving and fined.

(2) A 39-year-old man whose right leg had been amputated had for five years driven a car equipped with a hand-operated throttle and brake. When he was reversing the vehicle, his hand slipped off the brake lever and the car went into a ditch. He was not prosecuted. The customary blood analyses showed that the suspicion of his having consumed alcohol immediately before the accident was unsubstantiated.

(3) A 26-year-old man, whose right leg had been amputated and who was wearing an artificial limb, had been driving a normally equipped car for three years. The examining physician was of the opinion that the prosthesis was not fully adequate functionally. The driver ran into a car in front which braked suddenly. The court found him guilty of careless driving and he was fined.

It may justifiably be discussed whether these three incidents were anything more than occurrences which might have happened to non-disabled drivers in normally equipped vehicles. It is, however, possible that if the controls of the cars had been different the accidents might have been prevented; therefore in these cases the compensatory measures have been judged to be unsatisfactory.

In all the other accidents it was not possible to show that the type of technical equipment used was unsuitable or that the driver was unaccustomed to the special controls. These three cases constituted $0.6 \%$ of the drivers in the whole series, and the three road accidents formed $9 \%$ of the accidents in the whole series.

Total Number of Drivers Involved in Road Accidents or Serious Offences. The total number of drivers in the investigation and control series concerned in road accidents or serious traffic offences is shown in Table II, divided into age groups. The drivers involved have been counted, not the number of individual offences. The number of drivers with more than one road accident or serious offence was Io in the investigation series and $2 I$ in the control series. The number of drivers involved in accidents is equal in the two series, whereas the number of drivers with severe offences is noticeably less in the investigation series.

Exposure to Traffic The percentage distribution, according to annual driving distance and other driving data, of the drivers who answered the questionnaire is shown in Table III. Exposure to traffic, measured as the number of kilometres driven annually, is greater among the disabled drivers than among the drivers in the control series. This is suggested also by the fact that in the investigation series the vehicle was more commonly used for business purposes. The agreement between the two series was good as regards the type of driving, the time of day for driving, and the choice of route to and from the place of work. The majority of drivers drove in urban areas, during the daytime, and chose the same route to work every day. A relatively small

TABLE II

Number of Drivers Involved in Road Accidents or with Serious Offences OnLy, According to Age Group

\begin{tabular}{|c|c|c|c|c|c|c|c|c|}
\hline \multirow[b]{2}{*}{ No. of Drivers Involved in } & \multirow[b]{2}{*}{ Series } & \multicolumn{7}{|c|}{ Age Groups } \\
\hline & & 2I- & 26- & $31-$ & $4 I-$ & $51-$ & $>60$ & Total \\
\hline Road accidents & $\begin{array}{l}\text { Investigation } \\
\text { Control }\end{array}$ & $\begin{array}{l}5 \\
3\end{array}$ & $\begin{array}{l}5 \\
6\end{array}$ & $\begin{array}{r}7 \\
13\end{array}$ & $\begin{array}{r}12 \\
6\end{array}$ & $\begin{array}{l}4 \\
4\end{array}$ & $\begin{array}{l}2 \\
3\end{array}$ & $\begin{array}{l}35 \\
35\end{array}$ \\
\hline Serious offences & $\begin{array}{l}\text { Investigation } \\
\text { Control }\end{array}$ & $\begin{array}{l}5 \\
6\end{array}$ & $\begin{array}{l}2 \\
5\end{array}$ & $\begin{array}{r}5 \\
15\end{array}$ & $\begin{array}{l}8 \\
7\end{array}$ & $\begin{array}{l}3 \\
4\end{array}$ & $\begin{array}{l}2 \\
\mathbf{I}\end{array}$ & $\begin{array}{l}25 \\
38\end{array}$ \\
\hline
\end{tabular}


TABLE III

Percentage Distribution of Disabled Drivers and Drivers in the Control Series who Reported AnNual Driving Distance, PuRpose of Driving, and Areas of Driving

$\begin{array}{ll}\begin{array}{l}\text { Series } \\ \text { Investigation } \\ (\%)\end{array} & \begin{array}{l}\text { Control (\%) } \\ n=333\end{array} \\ n=316 & \end{array}$

Annual driving distance ( $\mathrm{km}$.)

I-4,999

5,000-9,999

10,000-19,999

20,000 and above

Total

$\begin{array}{rr}1 & 8 \\ 5 & 11 \\ 31 & 30 \\ 53 & 44 \\ 10 & 7 \\ 100 & 100\end{array}$

Purpose of driving

Mainly for business

Mainly for pleasure

No data given

Total

$\begin{array}{rr}84 & 49 \\ 13 & 43 \\ 3 & 8 \\ 100 & 100\end{array}$

Areas of driving

Mainly in urban areas

Mainly in rural areas

No data given

Total

$\begin{array}{rr}87 & 76 \\ 11 & 16 \\ 2 & 8 \\ 100 & 100\end{array}$

The percentages are given to the nearest whole number.

$\mathrm{n}=$ the number of drivers who answered the questionnaire.

number avoided the busier thoroughfares. In group I (extent of disability) the exposure to traffic was somewhat shorter than in groups 2 and 3 but agreed well with the exposure in the control series.

In order to facilitate a comparison between different disability groups and between different series with regard to traffic exposure, the percentage of drivers who reported having driven $10,000 \mathrm{~km}$. and more per year is stated: for the whole investigation series this was $63 \%$; for group I, $51 \%$; for group 2, $66 \%$; and for group 3, $64 \%$. For the control series the figure was $5 \mathrm{I} \%$.

Comparison of Investigation and Control Series In Table IV are presented the percentages of road accidents and of road accidents and serious offences counted together in the investigation series and in the control series. The distribution of accidents and offences in the subgroups of the investigation series and the most commonly occurring reasons for disablement are also given. The Table also shows the average period for possession of a driving licence as a disabled person during the ro-year period studied for the investigation series and subgroups.

During a Io-year period and with an average observation period of 6.5 years, $7 \cdot 1 \%$ of the drivers in the investigation series had been involved in a road accident and $12.2 \%$ had been involved in a road accident or had committed a serious traffic offence. These frequencies for accidents and offences agree with the corresponding figures in the control series, namely $7 \cdot 1 \%$ and $14.8 \%$. The exposure to traffic was, however, considerably less in the control series than in the investigation series.

As already pointed out, it is necessary, when comparing the control series and the investigation series, to avoid too sweeping conclusions in view of the characteristics of the control series available for comparison. It is, however, of interest to note that a control series to the previously reported study of chronically ill drivers in the county of Gothenburg and Bohus showed, for an exposure period similar to

\section{TABLE IV}

Percentage of Drivers With Road Accidents ONLy aNd/OR SERIOUS OfFenCES IN THE INVESTIGation SERIES, ACCORding to SUbGroups aND the Most Commonly Occurring CaUses of Disablement, aND IN THE CoNTrol Series

\begin{tabular}{|c|c|c|c|}
\hline \multirow{2}{*}{\multicolumn{2}{|c|}{$\begin{array}{l}\text { Investigation Group } \\
\text { or Cause of Disablement }\end{array}$}} & \multicolumn{2}{|c|}{ Percentage of Drivers with } \\
\hline & & $\begin{array}{l}\text { Traffic } \\
\text { Accidents }\end{array}$ & $\begin{array}{l}\text { Road } \\
\text { Accidents } \\
\text { and/or } \\
\text { Serious } \\
\text { Offences }\end{array}$ \\
\hline \multicolumn{2}{|c|}{$\begin{array}{l}\text { Whole investigation series } \\
\mathrm{m}=6.5 \\
\mathrm{n}=494 \\
0=63\end{array}$} & $7 \cdot 1$ & $12 \cdot 2$ \\
\hline n & $\begin{array}{l}\text { Group I } \\
\mathrm{m}=6 \cdot 7 \\
\mathrm{n}=94 \\
\mathrm{o}=5 \mathrm{I}\end{array}$ & $6 \cdot 4$ & $10 \cdot 6$ \\
\hline & $\begin{array}{l}\text { Group } 2 \\
m=5.9 \\
n=292 \\
0=66\end{array}$ & $6 \cdot 2$ & II 3 \\
\hline $\begin{array}{l}\text { c } \\
\text { n } \\
\text { n } \\
\text { o }\end{array}$ & $\begin{array}{l}\text { Group } 3 \\
m=6.9 \\
n=108 \\
0=64\end{array}$ & $9 \cdot 3$ & $14 \cdot 8$ \\
\hline $\begin{array}{l}\text { A } \\
\mathrm{p} \\
\mathrm{n} \\
\mathrm{n} \\
\mathrm{o}\end{array}$ & $\begin{array}{l}\text { After-effects of } \\
\text { poliomyelitis } \\
m=6 \cdot 7 \\
n=190 \\
0=69\end{array}$ & $6 \cdot 8$ & $8 \cdot 4$ \\
\hline $\begin{array}{l}\text { A } \\
\text { n } \\
\text { n } \\
\text { o }\end{array}$ & $\begin{array}{l}\text { Amputations } \\
m=6 \cdot 3 \\
n=76 \\
0=68\end{array}$ & $9 \cdot 2$ & $19 \cdot 7$ \\
\hline \multicolumn{2}{|l|}{$\begin{array}{l}\text { Control seri } \\
\mathrm{m}=6 \cdot 5 \\
\mathrm{n}=494 \\
\mathrm{o}=5 \mathrm{I}\end{array}$} & $7 \cdot 1$ & $14 \cdot 8$ \\
\hline
\end{tabular}


that of the present control series, that $7 \cdot 7 \%$ of the drivers had been involved in accidents and $15.3 \%$ had been involved in a road accident or had committed a serious traffic offence (Ysander, 1965, 1966).

\section{Different Disabilities Considered from the} Risk Point of View The second of the introductory questions concerned the extent to which any particular type of disablement might be a greater hazard from the traffic point of view than other forms of disablement.

It appears from Table IV that drivers with vehicles wholly operated by hand, or with vehicles in which certain controls were modified in an appropriate manner, have a lower accident and traffic-offence frequency than the whole investigation series. Drivers who can drive a vehicle without compensatory technical modifications show, however, an accident frequency and a total traffic-offence frequency which exceeds that of the whole investigation series. It is possible that this difference may be due to deficient ability in some of these drivers to drive the normally equipped vehicle, and that in this case a stricter assessment at the preliminary driving test might have reduced the number of road accidents and traffic offences. In this group there was a driver who, perhaps owing to an inadequate prosthesis, did not act with sufficient promptness when he had to brake suddenly (see p. 177 (3)).

Drivers suffering from the after-effects of poliomyelitis have the same accident frequency as groups I and 2, whereas drivers with amputations show frequency figures corresponding to group 3. The total traffic-offence frequency for these two causes of disablement are respectively the lowest and the highest. Of the drivers with amputations, $66 \%$ used prostheses, and $36 \%$ wore the prosthesis on the right arm or leg.

Table V shows the percentage distribution of the different losses of function and the percentage distribution of road accidents among these different disabilities. It is apparent from this Table that a disproportionately large number of road accidents occurred among drivers with loss of function in the right arm or the right leg. Of these drivers, $14 \%$ wore a prosthesis. All three accidents described above, which may have been due to inappropriately designed technical equipment or deficient prostheses, concerned drivers with loss of function in the right leg. There is reason to believe that the two ordinary control functions of the right leg are more difficult to compensate for than the simpler left-leg functions; drivers with loss of function in the left leg are responsible for a strikingly low share of the accidents. Even partial or total loss of function in
TABLE V

Percentage Distribution of Different Types of Loss of Function and Percentage Distribution of RoAd Accidents AMONG THESE TYPES

\begin{tabular}{lcc} 
Type of Loss of Function & $\begin{array}{l}\text { Drivers } \\
(\%)\end{array}$ & $\begin{array}{l}\text { Road } \\
\text { Accidents } \\
(\%)\end{array}$ \\
\hline Right arm or hand & 7 & 14 \\
Left arm or hand & 8 & 11 \\
Right leg or foot & 19 & 32 \\
Left leg or foot & 22 & 3 \\
Partial loss in both legs & 14 & 14 \\
Total loss in both legs & 19 & 20 \\
Other & 11 & 6 \\
Total & 100 & 100
\end{tabular}

both legs appears to be easier to compensate for than loss of function in the right leg. It also appears that loss of function in the right arm results in driving difficulties in spite of special aids.

Approximately $8 \%$ of the drivers in the investigation series had a driving licence before the onset of the disablement. The significance of previous driving experience before disablement is difficult to evaluate. As the average period of licence-holding before disablement in this group is as high as 15 years, it is possible that this had the effect of reducing accidents and traffic-offence frequency. Applying the criteria used earlier in this investigation to this small group, it is found that the frequency of accidents and offences during the disablement period agrees essentially with the figures for the whole investigation series, namely $7 \cdot 5 \%$ and $12.5 \%$ respectively.

\section{Conclusions}

This investigation, which might be regarded as representative of conditions in Sweden, shows that disabled drivers do not constitute an enhanced risk in traffic. Apparently their disabilities can be satisfactorily compensated for by applying various technical measures. During a ro-year period only three cases of traffic accidents have been found where the accident may possibly have been cause by defects in the technical equipment or a lack familiarity with it. The disabled drivers, furth more, do not have an accident or traffic-offe: frequency exceeding that of non-disabled driv. although this conclusion should be treated. reserve in view of the difficulties of obtaining entirely satisfactory control series.

Any measures taken to reduce still further the traffic risks associated with disabled drivers should be directed primarily to improving the compensatory technical modifications of the vehicle in those 
cases where the driver has loss of function in the right arm or right leg.

\section{REFERENCES}

Ganster, F. J. (1963). Z. ärzt. Fortbild., 57, 665.
SVCK (1960). Motorenquete 1959-1960. Information för vanförevården, 15,3 , no. 3 .

Svensk Författnings-Samling (1959). No. 163-165.

Witt, A. N. (1960). Hft. Unfallheilk., no. 62 p. 37.

Ysander, L. (1965). Läkartidningen, 62, 263. (1966). Brit. F. industr. Med., 23, 28. 